\title{
Design Status of the Advanced Closed Loop System ACLS for Accommodation on the ISS
}

\author{
Klaus Bockstahler ${ }^{1}$ and Joachim Lucas ${ }^{2}$ \\ Astrium GmbH, TO51, Friedrichshafen, Germany, 88039 \\ Johannes Witt ${ }^{3}$ \\ ESA-ESTEC, D/HSO, P.O. Box 299, 2200 AZ Noordwijk, The Netherlands
}

The Advanced Closed-Loop System ACLS is a regenerative life support system for closed habitats. With regenerative processes the ACLS covers the life support functions:

(1) Removal of carbon dioxide from the spacecraft atmosphere via a regenerative adsorption/desorption process.

(2) Supply of breathable oxygen via electrolysis of water,

(3) Catalytic conversion of carbon dioxide with hydrogen to water and methane.

ACLS will be accommodated in a double ISPR Rack which will contain all main and support functions like power and data handling and process water management. It is foreseen to be installed onboard the International Space Station (ISS) in the Columbus Module following lanch by HTV7 in 2017. Due to the regenerative processes applied in the ACLS it will allow a significant reduction of water upload to the ISS.

Following successful Preliminary Design Review and the first Safety Review the ACLS Engineering Model is being manufactured and tested.

The paper summarizes the development $\&$ hardware status and comprises an outlook on the upcoming design development of the ACLS

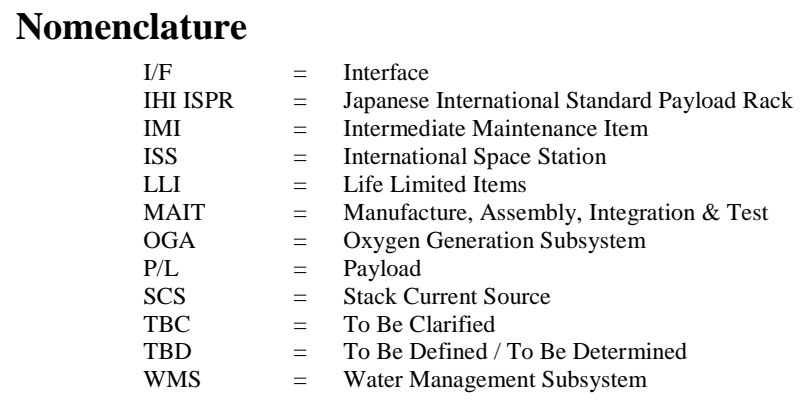

\section{Introduction}

After many years of predevelopment which has been reported regularly at ICES ${ }^{1}$ the ACLS project has started into full development in 2011. It is procured by ESA as a commercial service with reimbursements linked to actual ACLS performance and operation. This implies a more self-standing role given to industry with the responsibility of ESA limited to controlling the verification of twenty main performance requirements as well as safety and launcher interfaces. Industry is responsible for the development, qualification and procurement of all ACLS hardware and its operation, including training, until end 2020.

\footnotetext{
${ }^{1}$ ACLS Program Manager, Energy and Life Support Systems

${ }^{2}$ System Engineering Lead \& Expert, Energy and Life Support Systems

${ }^{3}$ System Engineer, ACLS Technical Lead
} 
ACLS will be qualified as non-mission critical system hardware. It is foreseen to be launched on HTV7 in 2017. Its operation will be coordinated with NASA in order to harmonise overall ISS ECLS operations.

\section{A. ACLS Functional Description}

ACLS is a system which can recycle oxygen from the $\mathrm{CO}_{2}$ that is produced by astronauts in manned space vehicles. Such recycling technology can reduce the re-supply to the ISS significantly. On longer duration missions like a lunar base or a manned mission to Mars closed loop (regenerative) systems will be essential to make such missions feasible.

ACLS has three major functions:

(1) The $\mathrm{CO}_{2}$ Concentration Subsystem (CCA) concentrates the $\mathrm{CO}_{2}$ from the cabin and thus controls the $\mathrm{CO}_{2}$ level to acceptable levels;

(2) In the $\mathrm{CO}_{2}$ Reprocessing Subsystem (CRA) or Sabatier reactor, hydrogen and $\mathrm{CO}_{2}$ react over a catalyst to form water and methane. The water is condensed and separated from the product gas stream and fed back to the electrolyser;

(3) The Oxygen Generation Subsystem (OGA) is an electrolyser which splits water into its constituents: oxygen and hydrogen.

Methane $\left(\mathrm{CH}_{4}\right)$ is vented overboard. In this way about $50 \%$ of the water needed for oxygen production can be produced on-board from the $\mathrm{CO}_{2}$ which is exhaled by the astronauts. The remaining water needs to be uploaded from ground.

Sized for a crew of 3, the operation of the ACLS onboard the ISS can save up to $450 \mathrm{~kg}$ of water upload per year.

The ACLS cycle is shown in Figure 1.

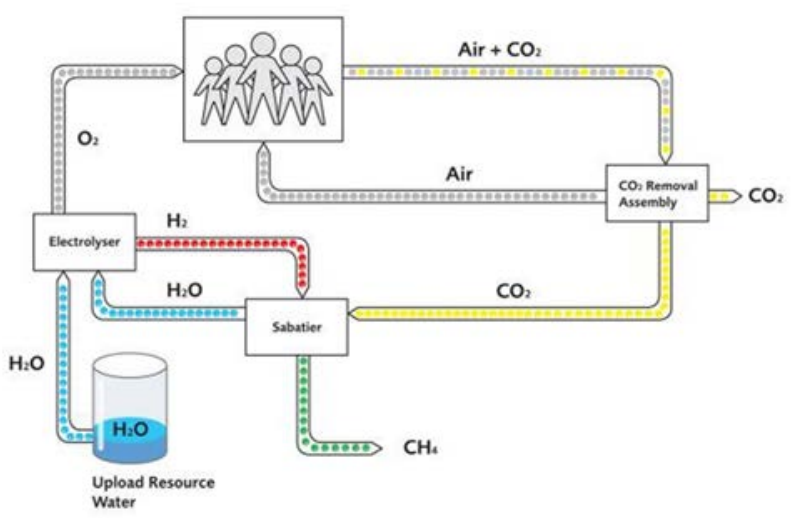

Figure 1: ACLS Closed Loop Schematics

\section{B. ACLS Requirements Outline}

The main performance requirements applied on ACLS design development are as follows:

(a) in continuous operation ACLS shall remove at least $3 \mathrm{~kg} /$ day $\mathrm{CO}_{2}$ from the cabin air at a nominal $\mathrm{CO}_{2}$ level of 4 $\mathrm{hPa}$;

(b) in continuous operation ACLS shall generate at least $2.52 \mathrm{~kg} / \mathrm{day} \mathrm{O}_{2}$ by the electrolysis of water;

(c) in continuous operation ACLS shall generate at least $1.2 \mathrm{~kg} /$ day of liquid water from the reaction of Hydrogen and $\mathrm{CO}_{2}$;

(d) crew time for preventive and corrective maintenance shall not exceed 8 hours per 1000 hours of full ACLS System opertation

(e) ACLS shall not require more than $5 \mathrm{~kg}$ of upload per 1000 hours of operation. 


\section{ACLS Design Status}

\section{A. ACLS in IHI ISPR Accommodation}

ACLS shall be installed and operated in the Columbus module in the A1 Rack position.

\section{Design Development}

ACLS is accommodated for launch, as a fully integrated (IHI) ISPR rack, see Figure 2, in the pressurized compartment of the Japanese HTV. The CCA's adsorber beds as well as ion exchange cartridges of the ACLS internal Water Management Subsystem (WMS) are designed for separate launch in soft-stowed configuration for thermal and mass optimisation.

ACLS subsystems are accommodated in the ISPR Rack inside extendable drawers which allow for easy access to items for maintenance. Maintenance is foreseen on unit level.

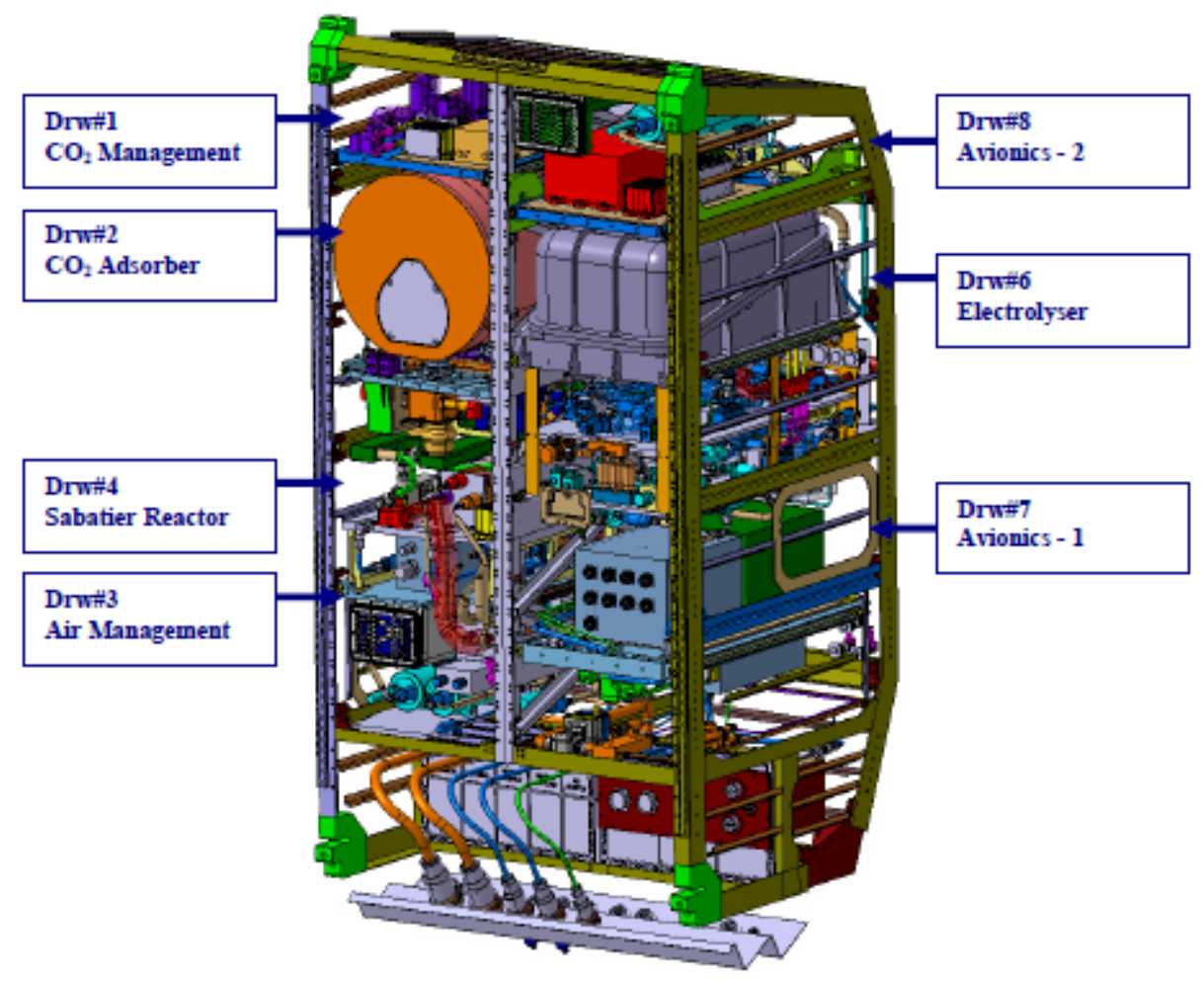

Figure 2: ACLS ISPR Rack Accommodation

On ACLS system level the following has been achieved:

- The Preliminary Design Review has been concluded

- Thermal and Structural Models have been finalized

- Detailed definition of Drawer Design and unit accommodation inside drawers including Maintainability assessment

- Manufacturing Release of all Engineering Model hardware

- Several workshops including support from NASA and the ESA astronaut corps helped to detail the Maintainability concept for ACLS

\section{Outlook}

In 2014 the complete ACLS EM will be integrated. EM testing will start at individual drawer and subsystem level. Testing of the integrated EM inside the rack will commence in the last quarter of 2014. 


\section{B. ACLS Subsystems}

\section{CO2 Concentration Subsystem (CCA)}

In continuous operation ACLS shall remove $\geq 3 \mathrm{~kg} /$ day $\mathrm{CO}_{2}$ from the cabin air at a nominal $\mathrm{CO}_{2}$ level of $4 \mathrm{hPa}$. Such requirement is satisfied by the CCA subsystem.

The $\mathrm{CO}_{2}$ loaded cabin air is flowing through the CCA's resin beds filled with ASTRINETM, which adsorbs the $\mathrm{CO}_{2}$. By slightly overheated steam supplied by the CCA's Steam Generator the $\mathrm{CO}_{2}$ is being desorbed, passed through a $\mathrm{CO}_{2}$ drying stage i.e. Water Recovery Unit and then fed to the CRA. Reference is made to Figure 3 .

The CCA contains three adsorber sections; they are operated such that the desorption phases overlap so that a continuous $\mathrm{CO}_{2}$ flow is provided to the CRA subsystem. The CO2 flow is measured by a mass flow meter; this allows to assess the functioning of the CCA

Each Adsorber Section comprises:

- a support structure,

- the Adsorber Bed, see Figure 4, including

- Astrine ${ }^{\mathrm{TM}}$ container,

- a volume expansion mechanism,

- temperature sensors;

- ducting for the fluid control

- appropriate thermal insulation and decoupling to minimize heat losses from the resin container and the steam generator during the regeneration phase;

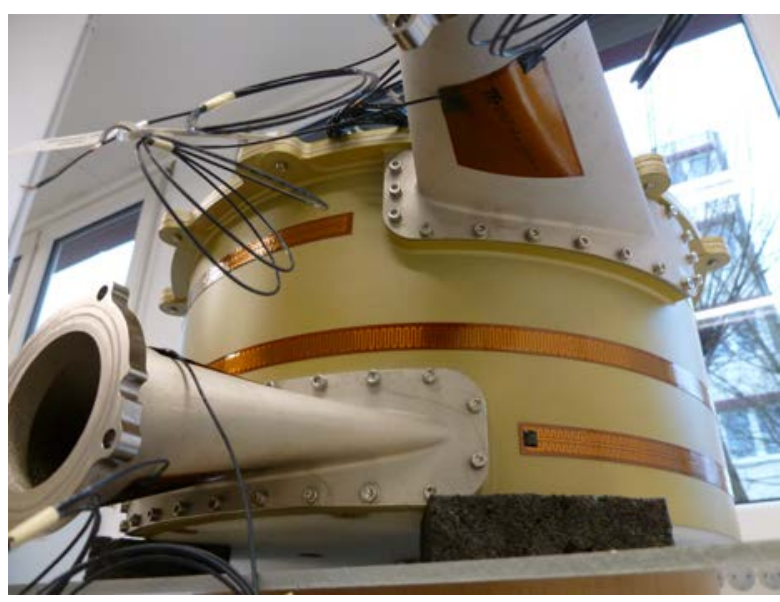

Figure 4: CCA EM2

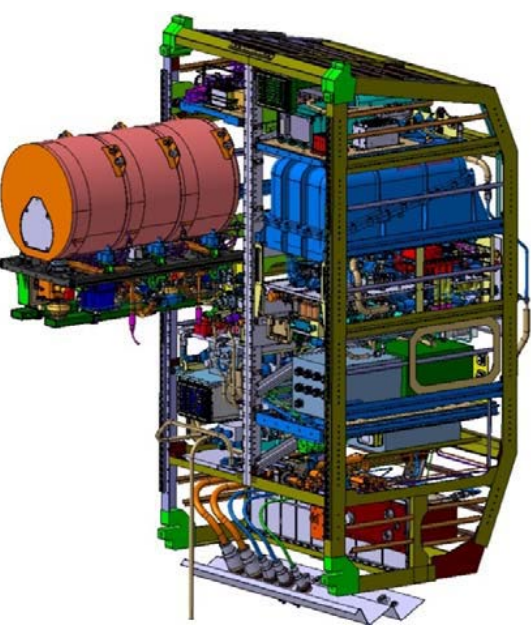

Figure 3: CCA Drawer 2 extended from Rack

- the steam generator.

- air inlet and outlet proportional modulating valves and solenoid valves for steam supply and $\mathrm{CO}_{2}$ release and Steam Generator flow control;

The CCA adsorber EM2, Fig. 4, has undergone extensive performance testing which proved the validity of the design improvements including mass minimisation and application of electrical heaters. While the $\mathrm{CO} 2$ amount per cycle increased by 15 percent, energy consumption and even more important, steam consumption per cycle decreased by more than 20 percent, see Figure 5. The CCA air ventilation fan EM, Figure 6, has undergone full testing validating its performance and the modifications of the commercial item. The muffler, Figure 7, after some additional optimisation will help to meet the very stringent noise requirement for the ACLS Rack of NC40 - 3dB.

\begin{tabular}{|l|l|l|l|}
\hline Indicator (per cycle) & EM1 & EM2 & Relative Change \\
\hline CO2 removal & $119.7 \mathrm{~g}$ & $138.4 \mathrm{~g}$ & $+15.6 \%$ \\
\hline Steam consumption & $418 / 4 \mathrm{~g}$ & $328.0 \mathrm{~g}$ & $-21.6 \%$ \\
\hline $\begin{array}{l}\text { Adsorber heat consumption + } \\
\text { output during desorpition }\end{array}$ & $\begin{array}{l}1230.8 \mathrm{~kJ} \\
\mathbf{1 4 0 9} \mathbf{~ J J}\end{array}$ & $\begin{array}{l}1389.0 \mathrm{~kJ} \\
\mathbf{1 2 7 4} \mathbf{~ J J}\end{array}$ & \begin{tabular}{l}
$+\mathbf{9 . 6} \%$ \\
\hline
\end{tabular}
\end{tabular}

Fiqure 5: CCA performance improvement 


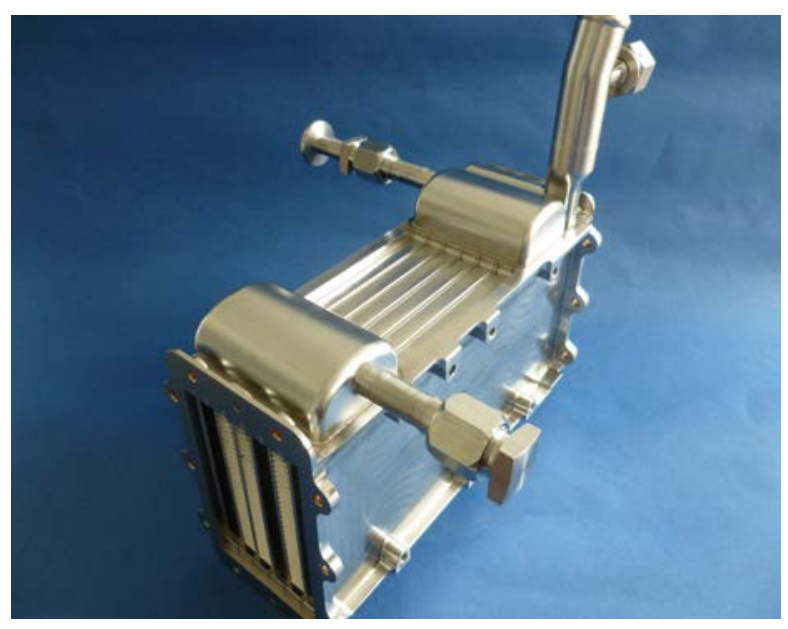

Figure 6: CCA Condensing Heat Exchanger

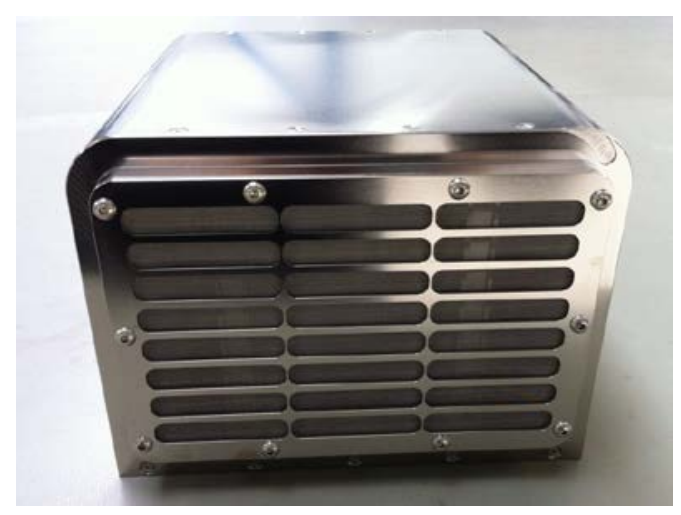

Figure 8: CCA Muffler

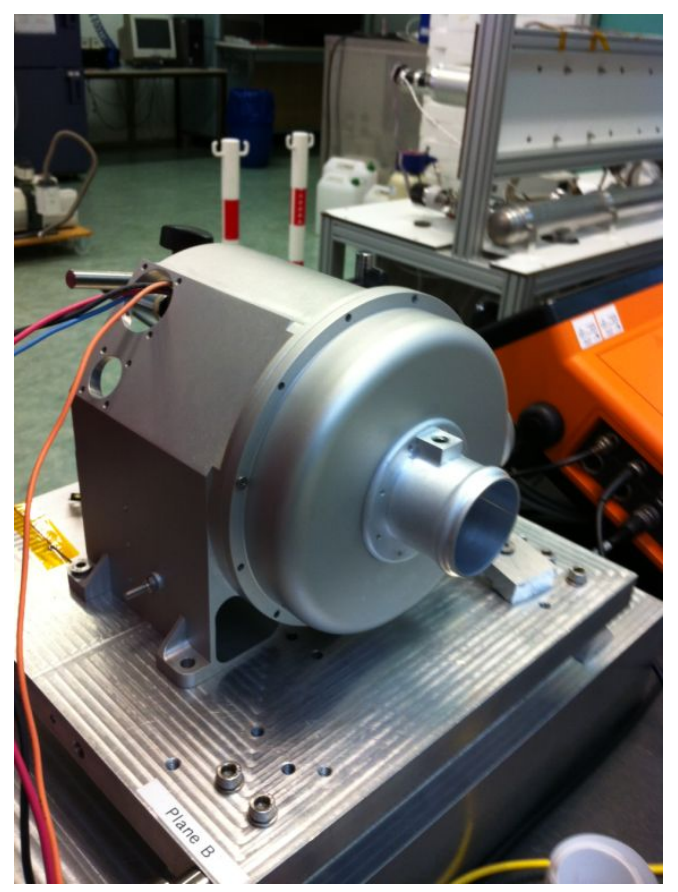

Figure 7: CCA FAN during Vibration Test

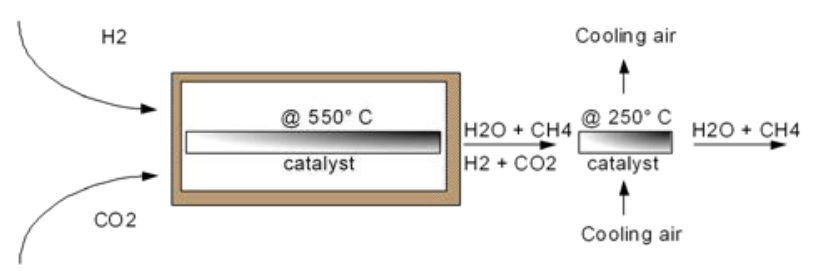

Figure 9: Sabatier principle with two reactor stages

\section{3. $\mathrm{CO}_{2}$ Reprocessing Subsystem (CRA)}

The CRA Sabatier reactor receives the $\mathrm{CO}_{2}$ directly from the CCA. Upstream of the reactors it is mixed with the hydrogen from the OGA, Figure 9.

Downstream of the Sabatier reactors a water recovery unit cools the hot product gases consisting of methane, water vapour and excess $\mathrm{CO}_{2}$ down. The condensate is routed to the water management subsystem for reuse. The product gases then flow to the vacuum control section and then to the vent line. The Sabatier reaches $90 \%$ hydrogen conversion and 53\% CO2 conversion.

The CRA Sabatier Reactor EM parts have been manufactured, Fig 10, and the EM is in final assembly.

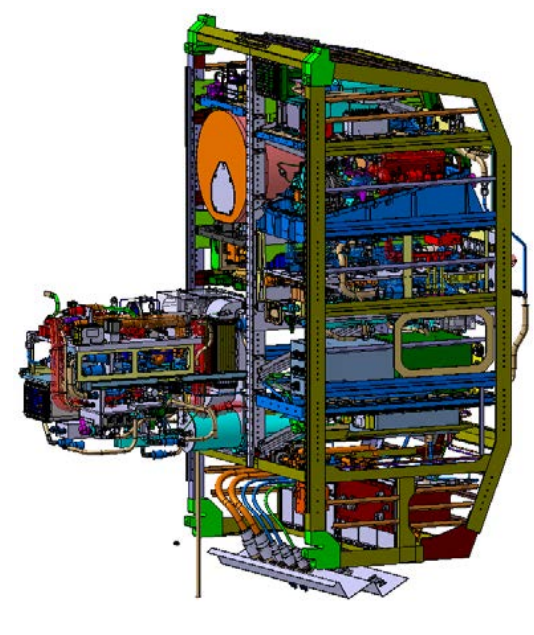

Figure 10: CRA Drawer 4 extended from Rack 


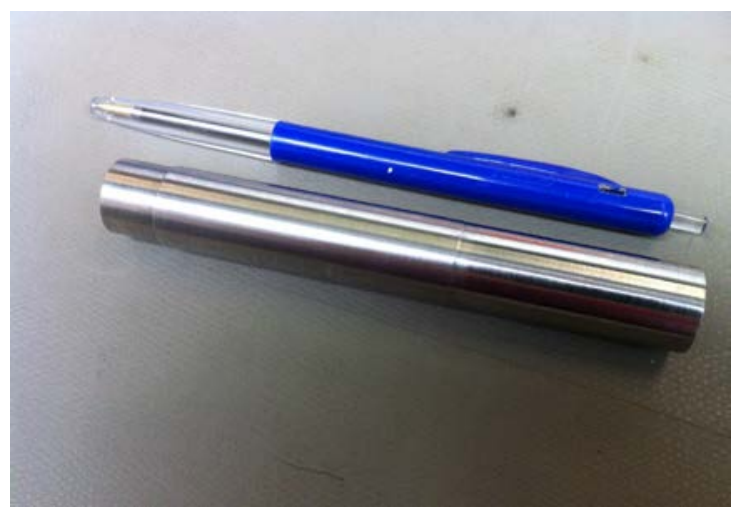

Figure 11: CRA Reactor 1 EM

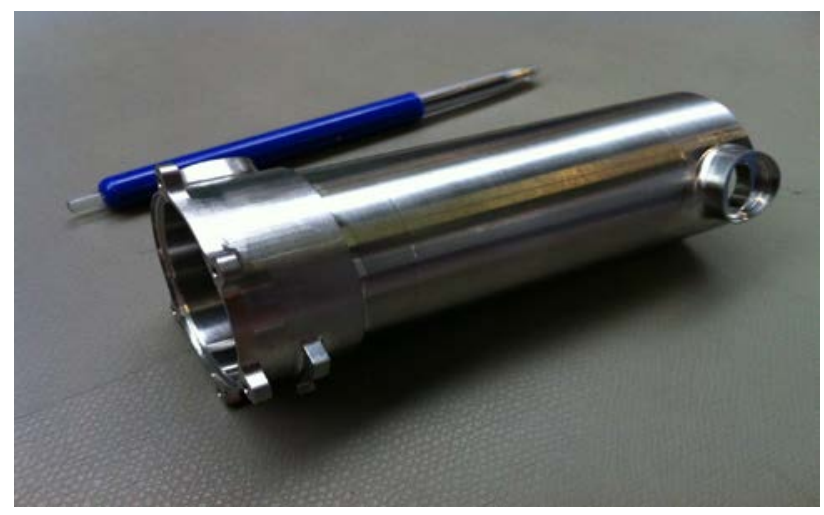

Figure 12: CRA Reactor 2 EM

\section{Oxygen Generation Subsystem (OGA)}

The ACLS OGA features a Fixed Alkaline Electrolyser: the feedwater is evaporated via a membrane into the diaphragm between the electrodes. In this way no additional gas/water separation is needed .

The oxygen produced by the OGA is released to the cabin while the hydrogen is routed to the CRA. All components which contain hydrogen at pressures above ambient are housed in a safety dome, see Figure 14. The hydrogen and oxygen outlets of the OGA are protected with a two-stage KOH filter, Figure 15, which serves to protect downstream equipment against accidental $\mathrm{KOH}$ release in case of a pressure control malfunction. The first $\mathrm{KOH}$ filters is equipped with a sensors to detect $\mathrm{KOH}$ overflow indicating filter saturation or failure.

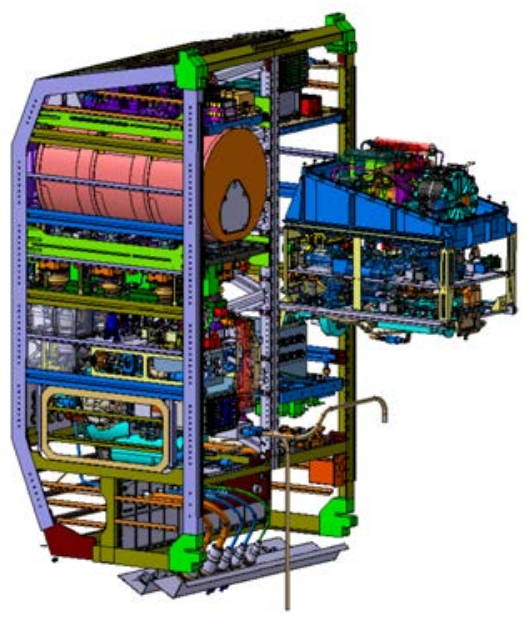

Figure 13: OGA Drawer 6 extended from Rack

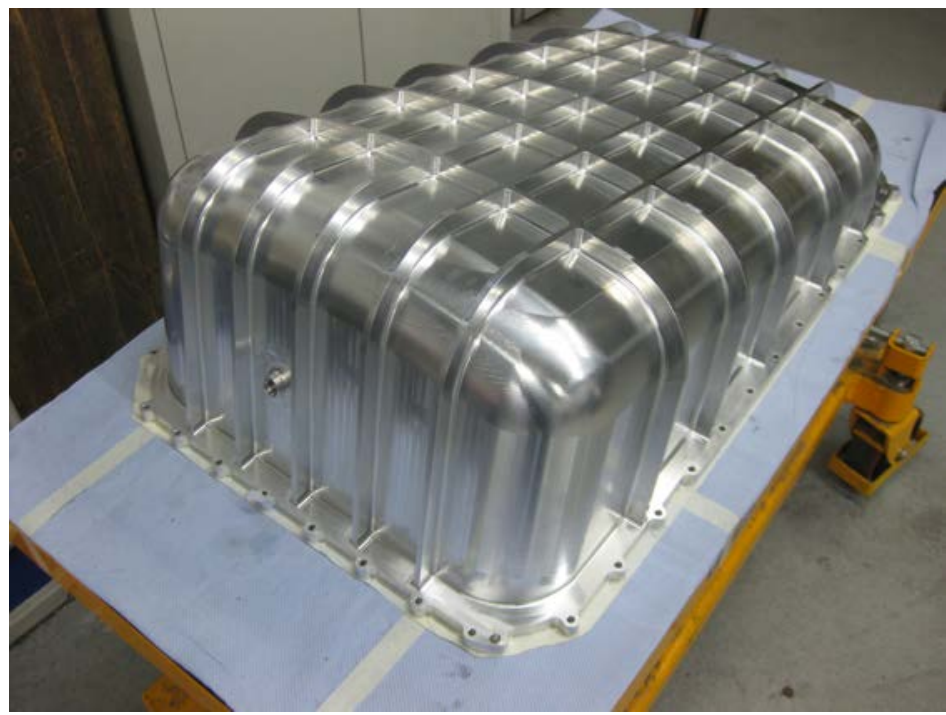

Figure 14: OGA Safety Dome

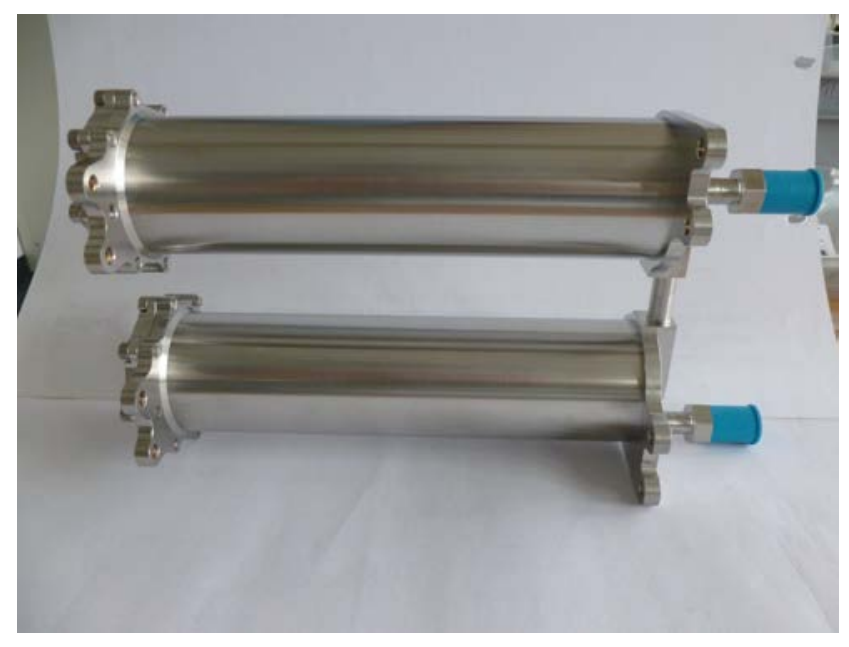

Figure 15: KOH Filter EM 


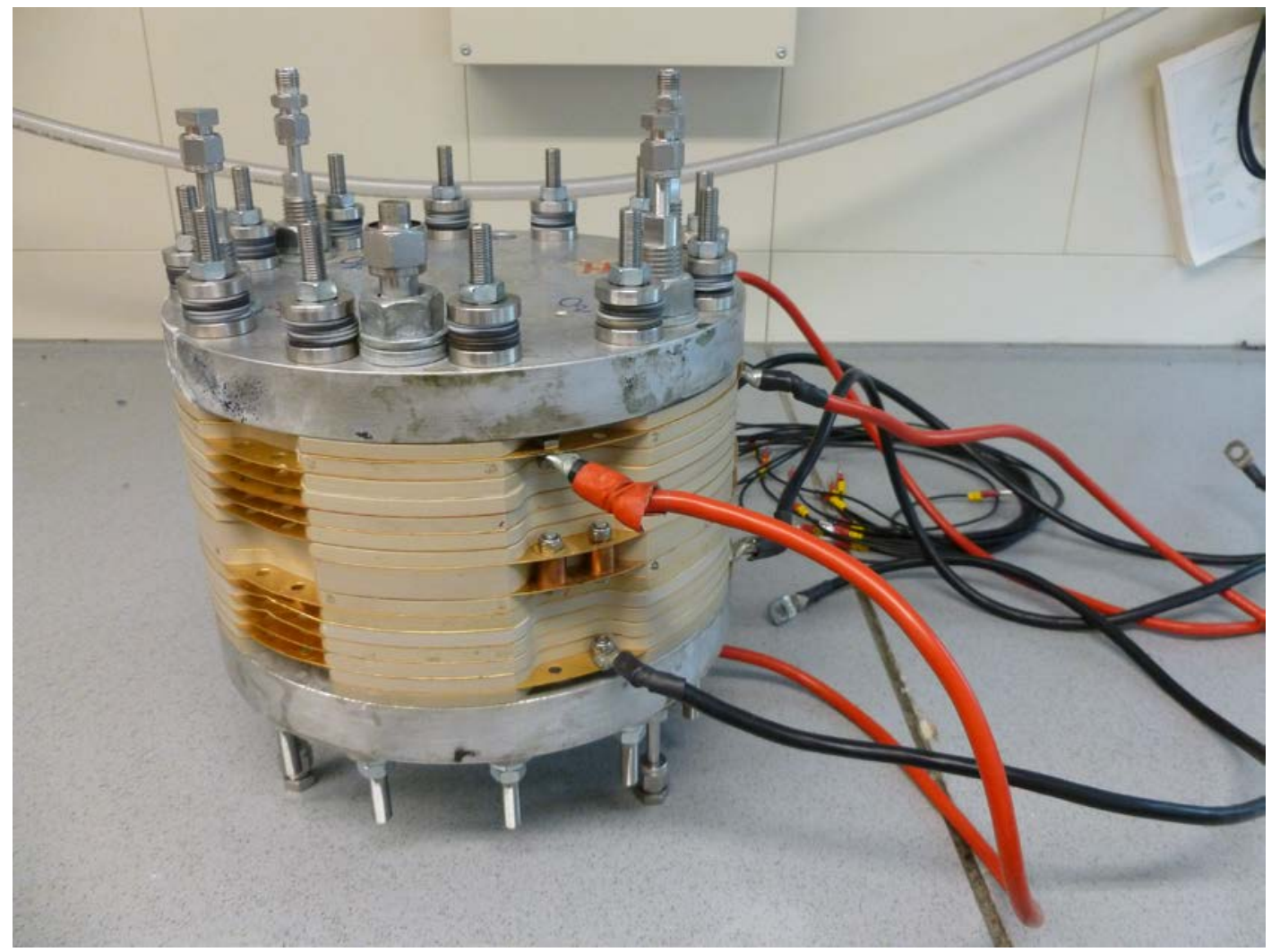

Figure 16: OGA Stack EM

\section{Water Management Subsystem (WMS)}

ACLS requires water

- for water electrolysis in the OGA, and

- for steam desorption in the CCA.

A built-in Water Management Subsystem shall handle all internal and external water sources of the ACLS system and shall provide the water quality as needed for the ACLS assemblies CCA and OGA or in case of water surplus inside ACLS the supply back to the station interface.

ACLS recovers internally condensate from the product gases at different locations; the condensate needs to be treated / decontaminated and conditioned by the ACLS water management before its re-use inside ACLS.

Although the CRA is producing water from the reaction of $\mathrm{CO} 2$ and $\mathrm{H} 2$ the resulting condensate cannot be fed directly into the electrolyser due to the possible presence of

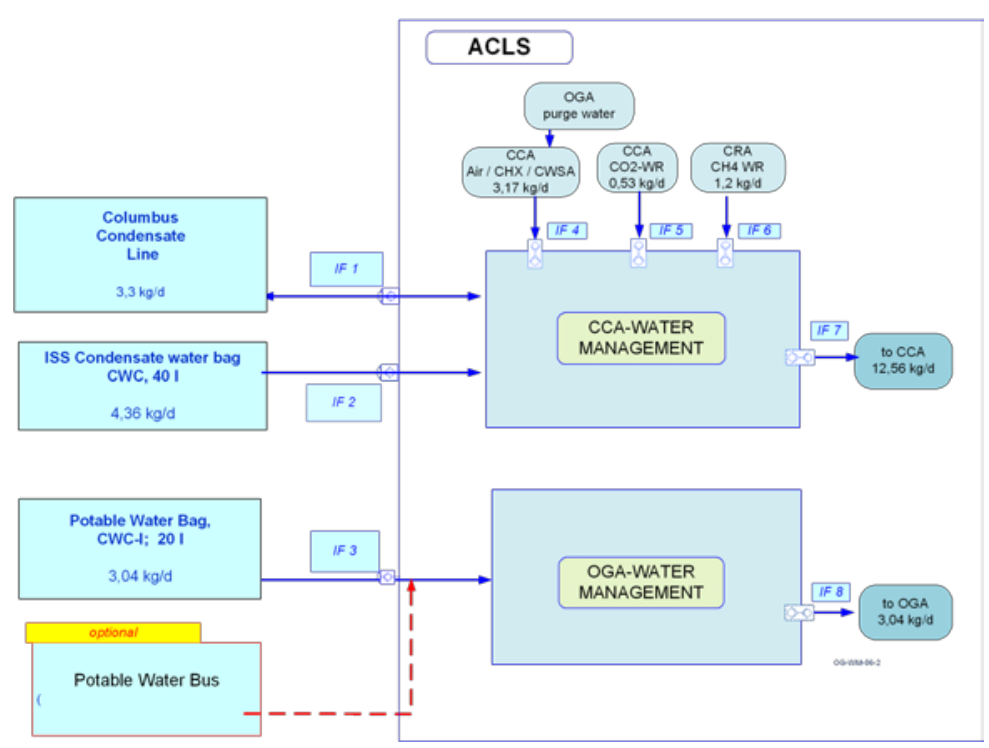

Figure 17: ACLS Water Supply Interfaces contaminants which could impact the operation of the OGA. The product water of the CRA is therefore fed towards the CCA where it is added to the water for 
steam desorption. The water used for steam generation is released from the CCA adsorber beds with the next adsorption cycle. It is recovered from the air passing through the beds via an internal CHX and some part is released towards the cabin where it is captured in the Humidity Control System. Overall the CRA product water will be regenerated in the US Water Recovery System.

The following external water sources are considered, see Figure 17:

- use of COLUMBUS water condensate line for water supply to CCA;

- condensate supply to CCA via external water bag CWC;

· potable water supply to OGA via external water bag CWC-I.

A further option being considered is the water supply to the OGA via dedicated potable water line, using the fuel cell water bus available in Node2.

Further design development of the WMS is detailed in a separate paper at ICES $2014^{2}$.

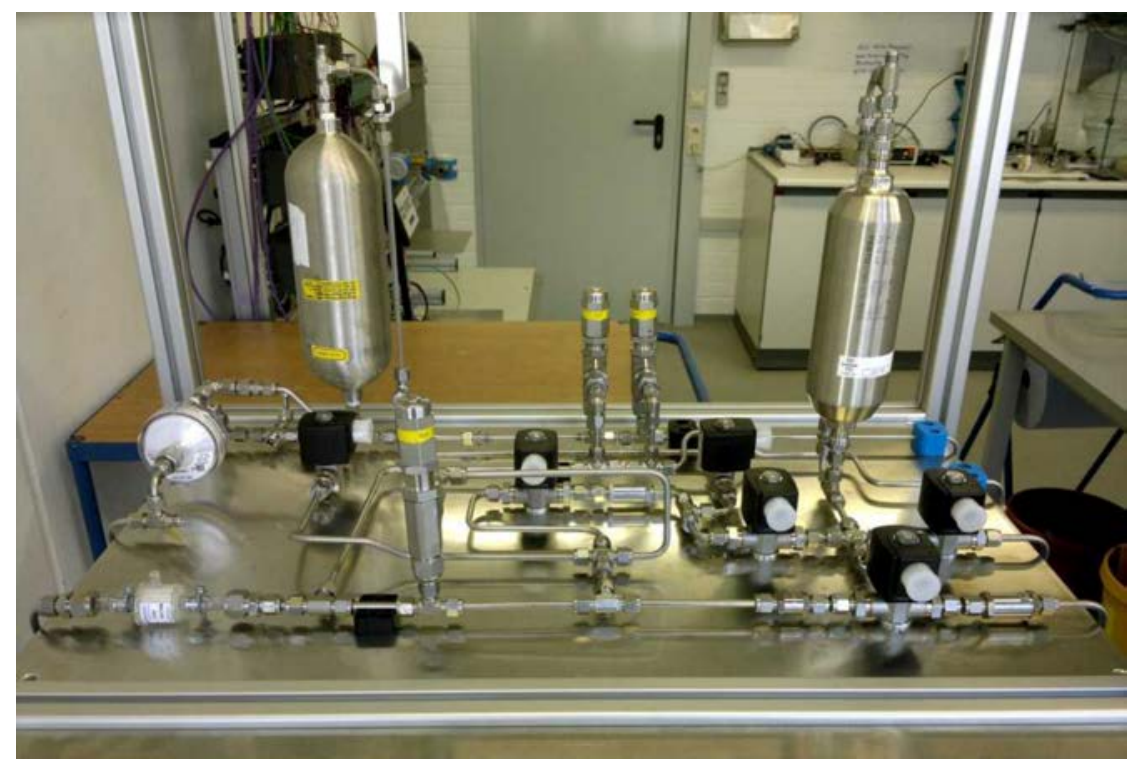

Figure 18: ACLS Water Management Hydraulic Breadboard

\section{Avionics Subsystem (including Software)}

The ACLS avionics subsystem controls the ACLS CCA, CRA and OGA processes and provides them with the necessary electrical power. In addition it includes the system element interfaces for data handling and power supply. ACLS avionics feature local Data Acquisition Units (DAU's) which route the many sensor signals needed to control ALCS processes via an internal data bus. Furthermore local power switching units are applied. This simplifies the harness significantly.

Development of the Avionics subsystem achieved

- Conclusion of the Avionics Subsystem PDR;

- Delivery of the System Controller EM

- Delivery of the Data Acquisition Unit EMs

- Release of all EM manufacturing.

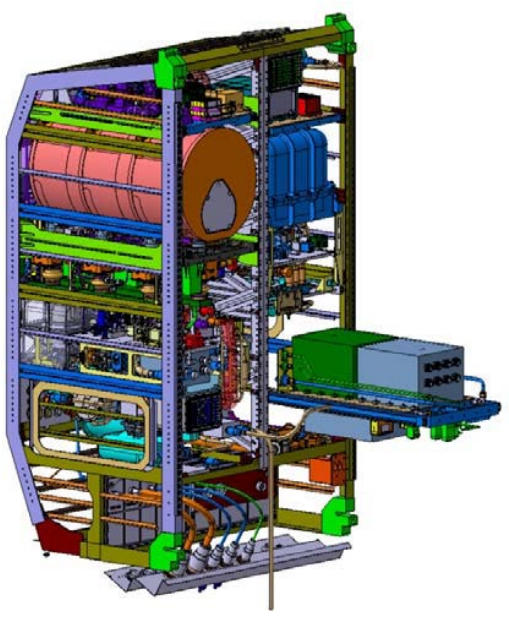




\section{Maintainability}

Throughout the design of the ACLS EM much attention has been given to the ease of maintaining ACLS. A detailed Maintainability Analysis supported by detailed CAD studies has been performed by studies of the accessibility of all units which need to be serviced during ACLS operational life. Several maintainability workshops have been held throughout 2013 with the support of NASA and the ESA astronaut corps. The requirements on upload and crew time are challenging; the limitation on upload requires exchange of single units. Access to and exchange of the units has been shown to be feasible even in the densely integrated environment of the ACLS Rack. The crew time requirement of less than 8 hours per 1000 hours of ACLS operations has been confirmed as well by the Maintainability Analysis. Obviously tests on the EM hardware needs to confirm the analytical findings.

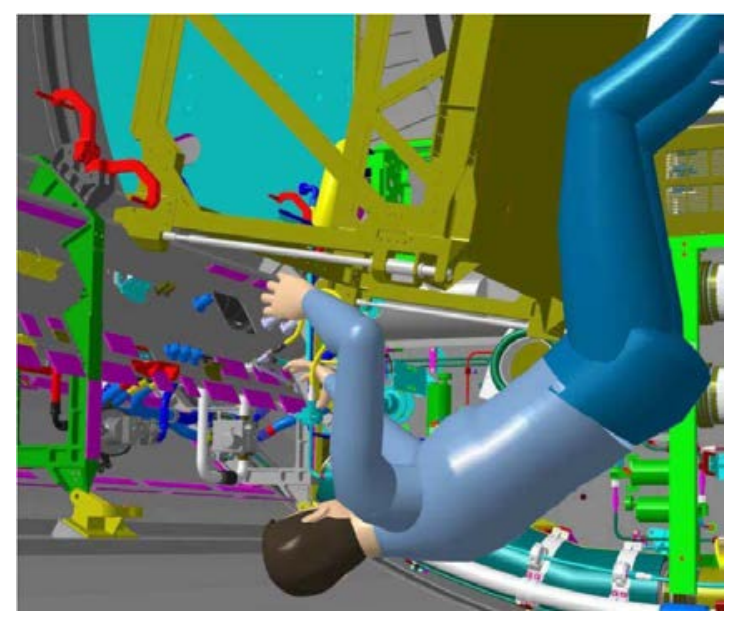

Figure 21: Installation of Condensate Line Extension to ACLS

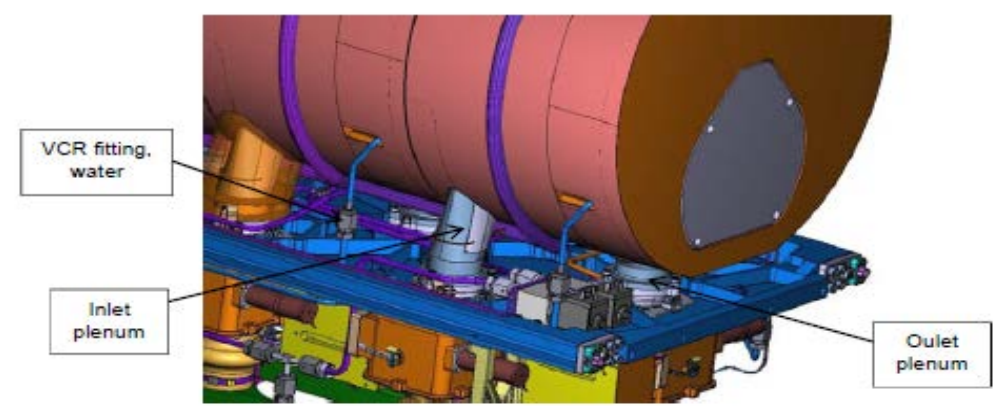

Figure 20: Exchange of CCA Adsorber Beds

\section{Conclusion}

ACLS is progressing well towards EM integration and test with CDR foreseen in the first half of 2015. ACLS stays on schedule for the launch on HTV7 in 2017.

\section{Acknowledgments}

The work has been performed under contract of the European Space Agency (ESA).

\section{References}

${ }^{1}$ Bockstahler, K.; Lucas, J.; Witt, J., Design Status of the Advanced Closed Loop System ACLS for Accommodation on the ISS, 42nd International Conference on Environmental Systems (ICES), 2013

${ }^{2}$ Boschieri, G.; Lamantea, M.; Bockstahler, K.; Funke, H; Witt, J. Development Status of WMS Sub-Assembly for water treatment within the ACLS Rack, 43rd International Conference on Environmental Systems (ICES), 2014 